\title{
Research on Deterioration Mechanism of Concrete Materials in an Actual Structure
}

\author{
Shiping Zhang, ${ }^{1}$ Xiang Dong, ${ }^{1}$ Houxian Zhang, ${ }^{1}$ and Min Deng ${ }^{2}$ \\ ${ }^{1}$ Department of Architecture Civil Engineering, Nanjing Institute of Technology, No. 1 Hongjing Road, Nanjing 211167, China \\ ${ }^{2}$ College of Materials Science and Engineering, Nanjing University of Technology, No. 5 Xin Mofan Road, Nanjing 210009, China
}

Correspondence should be addressed to Shiping Zhang; zhangshiping1982@gmail.com

Received 7 January 2014; Accepted 25 April 2014; Published 14 May 2014

Academic Editor: Osman Gencel

Copyright (c) 2014 Shiping Zhang et al. This is an open access article distributed under the Creative Commons Attribution License, which permits unrestricted use, distribution, and reproduction in any medium, provided the original work is properly cited.

The cause for deterioration of the concrete structure located in severe environment has been explored both in field and in laboratory. Serious cracking and spalling appeared upon surface of the concrete structure soon after the structure was put into service. Both alkali-aggregate reaction and freeze-thaw cycles may result in similar macro visible cracking and spalling. The possibility of alkali-aggregate reaction was excluded by both field survey and lab examination such as chemical analysis, petrographic analysis, and determination of alkali reactivity of aggregates. According to results of freeze-thaw cycles, impermeability testing, and microstructure analysis, it is deduced that the severe environmental conditions plus the relatively inferior frost resistance cause the deterioration of concrete. Usage of air entraining admixture can improve frost resistance and impermeability. Furthermore, new approaches to mitigate the deterioration of concrete used in severe environmental condition are discussed.

\section{Introduction}

Concrete structures are built to provide a service during a limited time period and, in some cases, the need for maintenance is foreseen [1]. However, recently durability of concrete has been a social concern due to the poor performance of concrete caused by various environmental, physical, and chemical factors such as corrosion of reinforcement bars due to carbonation or chloride ingress, freezing-thawing action, sulfate attack, alkali aggregate reaction, and so forth [2-8]. The resistance against these chemical erosions and physical deteriorations depends on the chemical composition and the microstructure of hardened cement matrix and on the environmental conditions to which the structure is exposed [9-11]. Correct understanding of the mechanism of deterioration can lead to improved specifications or construction techniques for new concrete exposed to similar condition [12].

According to statistics, most of concrete structures damaged are located in severe environment, which draws lots of attention for engineers and scientists. The temperature in severe environment may range from $-30^{\circ} \mathrm{C}$ in winter to $30^{\circ} \mathrm{C}$ during the summer; furthermore it varies from day to night sharply. The severe environment has caused serious problems for concrete structures. In the present work, a typical case was chosen to ascertain the deterioration mechanism. It is a matter of concrete materials in an airport runway. Serious cracking and spalling appeared upon surface of concrete shortly after the structure was put into service, as shown in Figure 1. The groundwater in situ is not aggressive according to geological survey by local authorities. Hence, the possibility of sulfate attack can be excluded. Since the alkali content of the cement used for the runway shoulder is a little high and the reactivity of the aggregates used is unknown, the occurrence of alkali-aggregate reaction is not eliminable. Both alkali-aggregate reaction and freeze-thaw cycles may result in similar macrostructurally visible cracking and spalling [13]. The present investigation is to identify which one is responsible for the deterioration of the concrete. Concrete cores were taken from the structure, as a reference; concrete samples were also made in laboratory. Various types of testing were carried out to characterize alkali-aggregate 


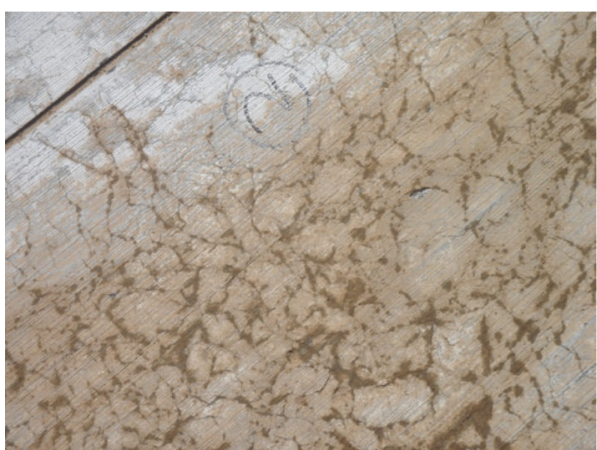

(a)

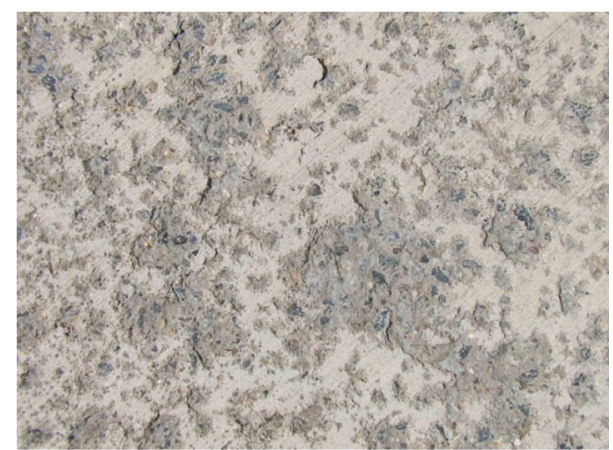

(b)

FIGURE 1: Deterioration characteristic of concrete in situ (a) cracking and (b) spalling.

reaction and frost resistance. In addition, impermeability and microstructure of the concrete in question were also examined to elucidate the deterioration mechanism.

\section{Samples and Test Methods}

2.1. Samples. Both concrete cores and standard samples were prepared. The concrete cores were taken from actual engineering, and standard samples used for freeze-thaw testing and impermeability testing were prepared in laboratory with the same raw materials and the same mix proportion as the actual structure. The cement used for determining alkali reactivity of aggregates is ordinary Portland cement produced by Onada Corp. in Jiangsu Province, China, which meets demands of the Rapid Test Method for Determining Alkali Reactivity of Sands and Rocks (CECS48-93) $\left(\mathrm{Na}_{2} \mathrm{O}_{\text {eq }}=\right.$ $0.53 \%)$. Chemical composition of the cement used for determining alkali reactivity of aggregates in lab is presented in Table 1.

2.2. Alkali-Aggregate Reaction. As well known, the coexistence of reactive aggregates, alkali, and water is prerequisite to the initiation of alkali-aggregate reaction (AAR) [14]. Map cracking, exudation of white gel, and reaction rim around aggregates are characteristic of AAR [15]. According to our field survey, there was neither map cracking nor white gel found. In addition, petrographic observations did not find reaction rim in polished section of the concrete. Accordingly, the possibility of AAR was evaluated through two aspects: alkali content of cement and reactivity of aggregates.

2.2.1. Alkali Content of Cement and Water. The experimental method and procedure for analysis of chemical composition of cement used for the runway shoulder was in accordance with Chinese National Standard GB/T 176-1996. The alkali content in water used for the concrete was detected using a type $6400 \mathrm{~A}$ flame spectrometer.

2.2.2. Reactivity of Aggregates. The Rapid Test Method for Determining Alkali Reactivity of Sands and Rocks (CECS4893) was chosen to assess the reactivity of aggregates.
TABLE 1: Chemical composition of the cement used for determining alkali reactivity of aggregates.

\begin{tabular}{lccccccc}
\hline \multirow{2}{*}{ Sample } & \multicolumn{7}{c}{ Chemical composition (wt\%) } \\
& $\mathrm{CaO}$ & $\mathrm{SiO}_{2}$ & $\mathrm{Al}_{2} \mathrm{O}_{3}$ & $\mathrm{Fe}_{2} \mathrm{O}_{3}$ & $\mathrm{MgO}$ & $\mathrm{SO}_{3}$ & $\mathrm{Na}_{2} \mathrm{O}_{\text {eq }}$ \\
\hline Cement & 63.1 & 22.74 & 6.46 & 3.56 & 1.60 & 0.81 & 0.53 \\
\hline
\end{tabular}

The dimensions of the specimens were $10 \mathrm{~mm} \times 10 \mathrm{~mm} \times$ $40 \mathrm{~mm}$, and cement to aggregate ratio was $2: 1,5: 1$ and $10: 1$, respectively. The samples were cured in humid air at $20^{\circ} \mathrm{C} \pm$ $2^{\circ} \mathrm{C}$ for $24 \mathrm{~h}$ after casting. Then they were demolded, the initial length of the micro bar being measured. Afterward, the samples were autoclaved in water at $100^{\circ} \mathrm{C}$ for $4 \mathrm{~h}$ and then in $8.2 \%$ alkali solution at $150^{\circ} \mathrm{C}$ for $6 \mathrm{~h}$. The final length of the micro bar was measured again. Aggregates are reactive if the maximum expansion of the micro bar is $\geq 0.1 \%$ based on the criterion specified by CECS48-93. Otherwise, aggregates are nonreactive. Besides, petrographic analysis and X-ray diffractometry of aggregates were performed using OLYMPUS BH-2 (made in Japan) and ARL X'TRA (made in USA), respectively.

2.3. Frost Resistance Testing. Rapid freezing method has been commonly used to evaluate frost resistance. The testing procedure carried out in this investigation conformed to Chinese National Standard GB/T 50082-2009. In a single cycle, the temperature of the specimens cooled from 6 to $-15^{\circ} \mathrm{C}$ and then warmed to $6^{\circ} \mathrm{C}$ within approximately $2.5-3 \mathrm{~h}$. Both freezing and thawing were performed in water. Since the tested cores were not standard samples in size, the relative dynamic elastic modulus failed to be examined. Standard concrete samples were made in laboratory with the same mix proportion and materials as the concrete structure. Both mass loss and loss of dynamic modulus of elasticity were checked for the standard samples.

2.4. Impermeability Testing. Impermeability of the cores from the structure was tested. Since the tested cores were not 


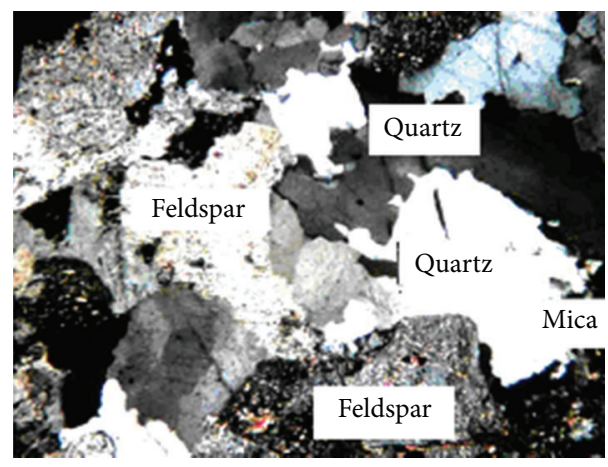

Figure 2: Micrographs of sands.

standard samples in size, impermeability test was carried out by using an apparatus of type SS15 (made in China) originally for mortar permeability testing. Impermeability of standard samples prepared in laboratory was carried out according to GB/T 50082-2009. The samples were applied by pressurized water, and the pressure was gradually increased until the samples were penetrated by pressurized water. The maximum pressure which the sample can afford was used to evaluate the impermeability.

2.5. Microstructure Analysis. Polished sections of the cores taken from the structure were observed using microscope OLYMPUS XZ-2 (made in Japan). Scanning electron microscopy (SEM) (JSM 5900, made in Japan) and mercury intrusion porosimetry (MIP) (GT-60, made by Quantachrome Co., USA) were also used here.

\section{Results and Discussion}

3.1. Alkali-Aggregate Reaction. Table 2 shows chemical composition of cement used for the structure. The equivalent alkali content of the cement is calculated to be $0.62 \%$ according to the commonly recognized formula $\mathrm{Na}_{2} \mathrm{O}_{\text {eq }}=\mathrm{Na}_{2} \mathrm{O}+$ $0.658 \mathrm{~K}_{2} \mathrm{O}$, a little higher than $0.60 \%$ which is the maximum value of low-alkali cement. Table 3 presents the alkali content of water used for the structure. Apparently, the alkali content of the water is negligible. Table 4 gives testing results for alkali reactivity of aggregates. The maximum expansion of micro bars is $0.053 \%$ and $0.046 \%$ for sand and crushed stone, respectively, less than the limit of $0.10 \%$. So, the aggregates are identified to be nonreactive according to the criterion. In order to evaluate the reactivity of aggregates, both coarse and fine aggregates were analyzed by petrographic method, and the results about that were shown in Figures 2 and 3 , respectively. From petrographic analysis of aggregates, it is found that sands mainly contain quartz, feldspar, and mica. For the crushed stone, the main components are quartz and mica. Furthermore, these mineral compositions are of well crystallization, which indicates being nonreactive. Therefore, both coarse aggregates and fine aggregates are nonactive.

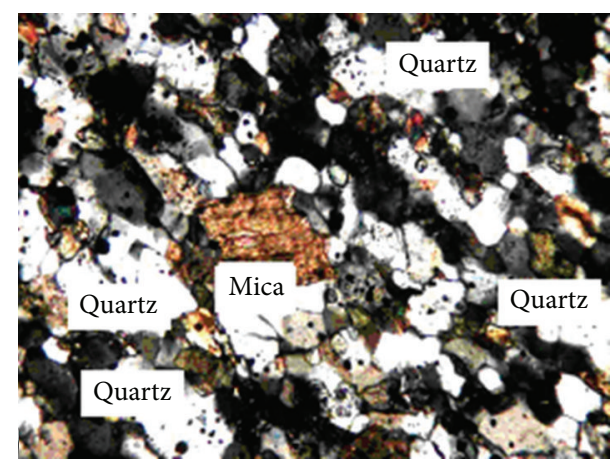

Figure 3: Micrographs of crushed stone.

TABLE 2: Chemical composition of cement.

\begin{tabular}{lccccccc}
\hline \multirow{2}{*}{ Sample } & \multicolumn{7}{c}{ Chemical composition (wt\%) } \\
& $\mathrm{CaO}$ & $\mathrm{MgO}$ & $\mathrm{Fe}_{2} \mathrm{O}_{3}$ & $\mathrm{Al}_{2} \mathrm{O}_{3}$ & $\mathrm{SiO}_{2}$ & $\mathrm{Na}_{2} \mathrm{O}_{\text {eq }}$ & $\mathrm{SO}_{3}$ \\
\hline Cement & 61.74 & 1.57 & 3.54 & 5.37 & 21.84 & 0.62 & 2.15 \\
\hline
\end{tabular}

TABLE 3: Chemical analysis of water.

\begin{tabular}{lccccc}
\hline Sample & $\mathrm{pH}$ & $\begin{array}{c}\mathrm{K}_{2} \mathrm{O} \\
(\%)\end{array}$ & $\mathrm{Na}_{2} \mathrm{O}(\%)$ & $\begin{array}{c}\text { Insoluble } \\
(\mathrm{mg} / \mathrm{L})\end{array}$ & $\begin{array}{c}\text { Soluble } \\
(\mathrm{mg} / \mathrm{L})\end{array}$ \\
\hline Water & 6.86 & 0 & $2.3 \times 10^{-3}$ & 7.00 & 272.00 \\
\hline
\end{tabular}

TABLE 4: Test results of alkali reactivity of aggregates.

\begin{tabular}{lcccc}
\hline Sample & \multicolumn{3}{c}{ Expansion (\%) } & $\begin{array}{c}\text { Alkali-reactivity } \\
\text { identification }\end{array}$ \\
\hline $\begin{array}{l}\text { Sand } \\
\text { Crushed } \\
\text { stone }\end{array}$ & 0.030 & 0.049 & 0.053 & Nonalkali reactive \\
& 0.029 & 0.034 & 0.046 & Nonalkali reactive \\
\hline
\end{tabular}

3.2. Frost Resistance. For the concrete core from practical engineering, deterioration due to freeze-thaw cycles is assessed by mass loss during freeze-thaw cycling. Figure 4 showed the mass loss of samples during freeze-thaw cycles. According to results in Figure 4, mass loss of the cores is greater than $5 \%$ after 76 freeze-thaw cycles. According to the criterion specified by GB/T 50082-2009, a sample is damaged completely when the mass loss reaches $5 \%$. So, these concrete cores only can resist about 76 freeze-thaw cycles. For the concrete samples prepared in laboratory, deterioration due to freeze-thaw cycles is assessed by both mass loss and dynamic modulus of elasticity during freeze-thaw cycling. Figure 5 presented the freeze-thaw test results for standard samples. For number 1 sample, air entraining admixture was added. It is evident that similar to freeze-thaw test results of the cores, the mass loss of sample 2 reaches $5 \%$ in about 80 cycles. The change rate of mass loss and dynamic modulus of elasticity of standard sample 1 is much lower than that of 


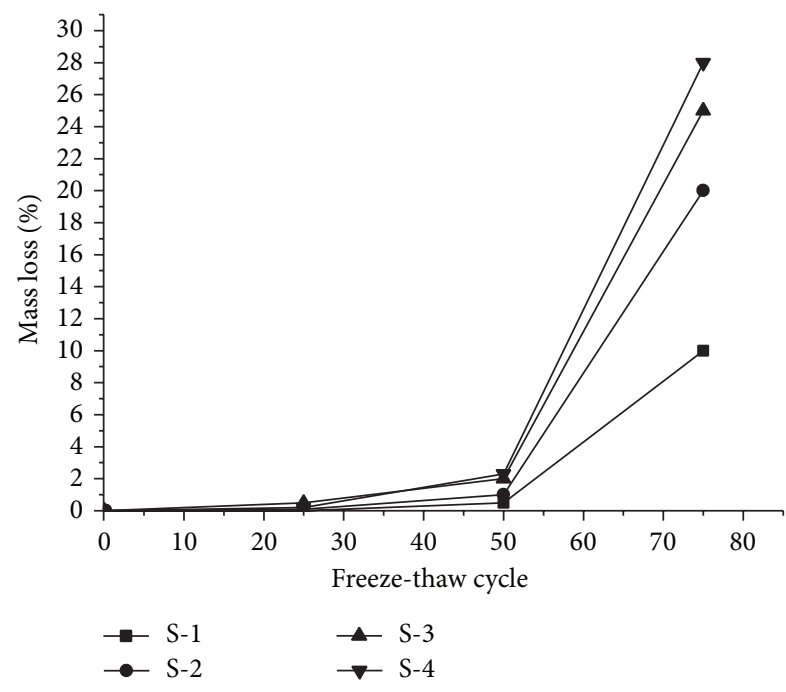

Figure 4: Mass loss of concrete cores after freeze-thaw cycles.

TABLE 5: Impermeability of concrete cores.

\begin{tabular}{lc}
\hline Sample & Hydraulic pressure $(\mathrm{MPa})$ \\
\hline S-5 & 0.6 \\
S-6 & 0.4 \\
S-7 & 0.8 \\
1 & 1.3 \\
2 & 0.6 \\
\hline
\end{tabular}

standard sample 2. In general, both of the cores taken from the structure and the standard samples without air entraining admixture made in laboratory exhibited poor frost resistance.

3.3. Impermeability Testing. During impermeability testing, the maximum pressure of samples was measured. The higher pressure sample bore, the greater impermeability concrete had. Table 5 presents testing results of impermeability of both concrete cores from project site and standard samples prepared in laboratory. It is obvious that the cores (S-5, S-6, S-7) from the actual structure exhibit poor impermeability. For standard samples made in laboratory, sample 2 which did not use air entraining admixture also presented poor impermeability, while sample 1 which contained air entraining admixture sustained almost twice hydraulic pressure as high as samples 1 . Here, the only difference between sample 1 and other samples is in the usage of air entraining admixture. Therefore, the impermeability of the concrete with air entraining admixture is much better.

3.4. Microstructure Analysis. Microstructures of concrete samples from actual engineering were evaluated through polarizing microscope and SEM. Photos obtained from polarizing microscope were shown in Figure 6, and Figure 7 gave the results obtained by SEM. Observations in Figure 6(a) showed that interstice exists in the interface between mortar

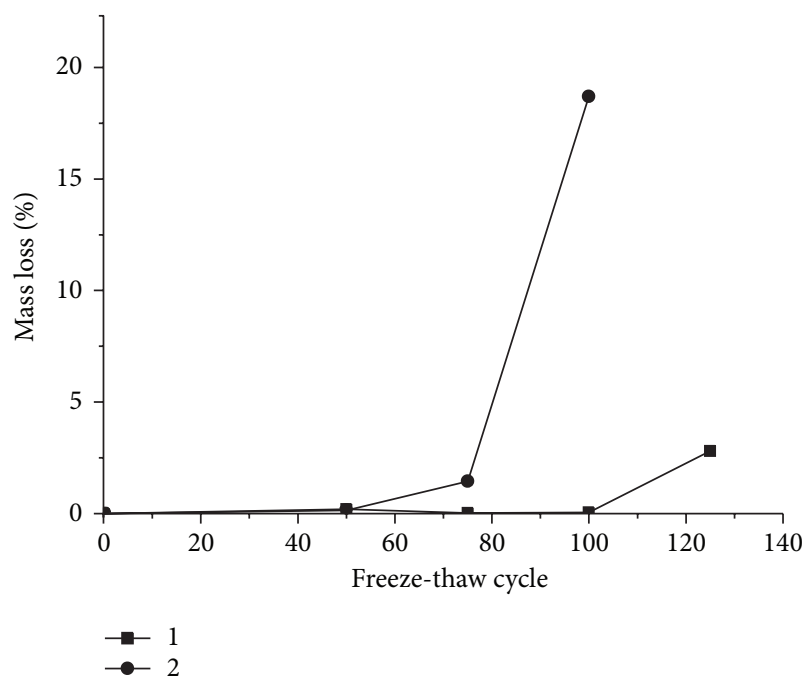

(a)

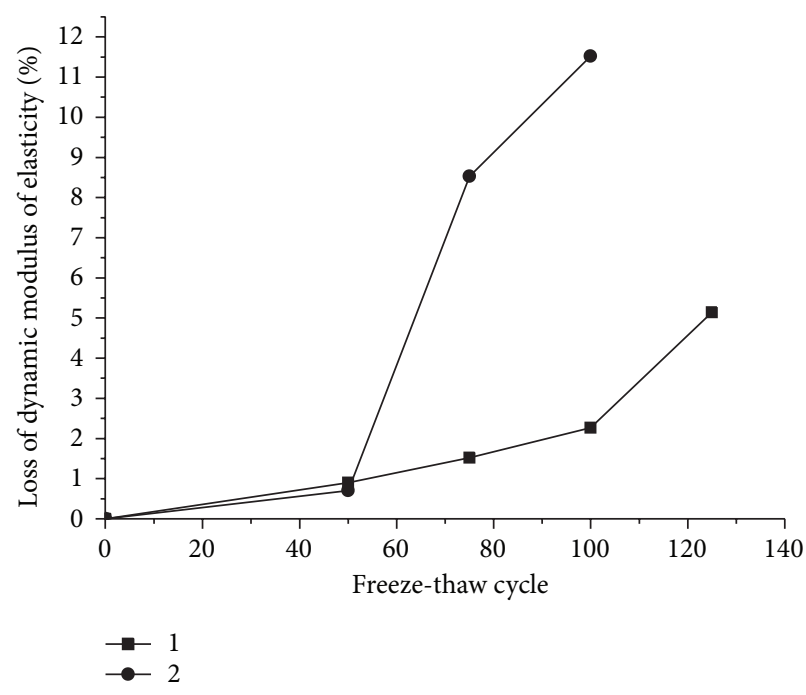

(b)

FIGURE 5: Freeze-thaw test results for standard samples (a) mass loss and (b) loss of dynamic modulus of elasticity.

and aggregate. Furthermore, micro cracks also appeared in the paste, as shown in Figure 6(b). Similarly, there were also cracking and pores in mortar, as shown in Figure 7. Based on microstructure analysis, the concrete cores presented poor structure. The pore structure of cement-based materials is one of its most important characteristics and strongly influences both its mechanical properties and its durability. Table 6 presented total pore volume, porosity, and average pore diameter of three cores examined by MIP. In the MIP results, sample 1 and sample 2 stand for standard sample with and without air entraining admixture prepared in lab, respectively, while sample $S$ means the concrete core from actual structure. It is to be noted that compared with sample 1 , the total pore volume, porosity, and average pore diameter of the sample 2 and sample $S$ are considerably higher. In addition, the sample 2 and sample $S$ contain appreciably 
TABLE 6: Pore structure of concrete cores.

\begin{tabular}{lcccccc}
\hline Sample & Total volume $\left(\mathrm{mm}^{3}\right)$ & Porosity $(\%)$ & Average pore size $(\mathrm{nm})$ & $d \geq 100 \mathrm{~nm}(\%)$ & $50 \mathrm{~nm}<d<100 \mathrm{~nm}(\%)$ & $d \leq 50 \mathrm{~nm}(\%)$ \\
\hline 1 & 38.60 & 8.87 & 47.70 & 28.98 & 18.17 & 52.85 \\
S & 96.80 & 18.64 & 71.20 & 39.27 & 19.20 & 41.53 \\
2 & 92.20 & 17.94 & 83.00 & 44.5 & 16.35 & 39.15 \\
\hline
\end{tabular}

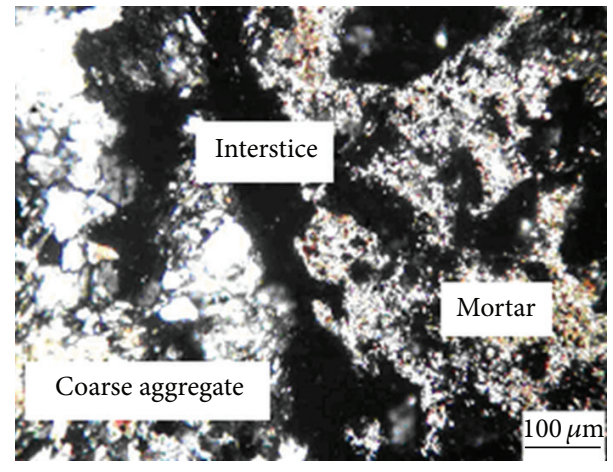

(a)

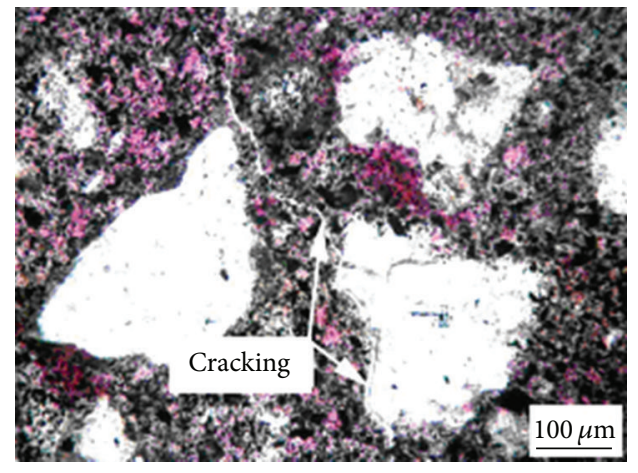

(b)

FIGURE 6: Photos of microstructure (a) interstice between coarse aggregate and mortar and (b) cracking in the mortar.

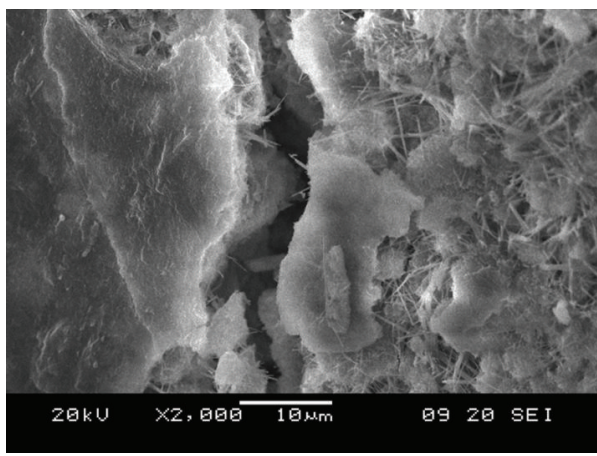

(a)

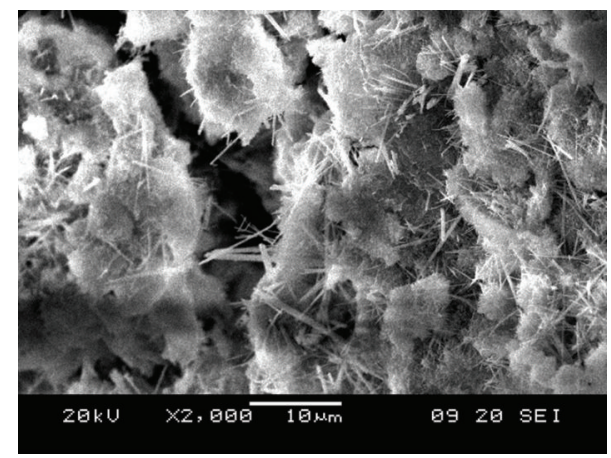

(b)

FIGURE 7: SEM images of concrete cores (a) cracking in the mortar and (b) pores in the mortar.

larger amount of pores with $d \geq 100 \mathrm{~nm}$ than the sample 1 , which are considered to be harmful, according to $\mathrm{Wu}$ and Lian [16]. Therefore, sample 1 showed relative better pore structure, and it indicated that air entraining admixture improved pore structure.

3.5. Discussion of Concrete Durability. Although alkali content in cement used for the structure exceeds the limit value $0.60 \%$ of low-alkali cement, the aggregates used are determined to be nonreactive. In addition, the characteristics of alkali-aggregate reaction such as map cracking, white gel, and reaction rim around aggregates have not been found both in field and in lab. These research findings suggest that alkali-aggregate reaction is unlikely to take place for the present case. Based on results of freeze-thaw testing and impermeability testing, it can be deduced that the concrete cores from actual engineering present poor frost resistance and impermeability. Besides, the standard sample without air entraining admixture made in lab also showed poor frost resistance and impermeability, while the standard sample with air entraining admixture made in lab showed excellent frost resistance and impermeability. Meanwhile, according to climate data, the temperature in situ varies sharply. So, it is the severe weather conditions combined with the poor frost resistance and impermeability that bring about the deterioration of the concrete structure. To solve this problem, usage of air entraining admixture is effective.

Undoubtedly, the durability of concrete used in severe environment should be taken as a top priority. A wholly new program is currently under way in our lab. The objective of the program is to fabricate large area concrete road slabs of long service lifetime. The key point of the program is to improve the microstructure, augment the strength, and 
enhance the restraining stress. The measures being taken include addition of chemical additives and expansive mineral admixtures, utilization of steel bar enforcement, and structure design. It is hoped that the ongoing research work may contribute to the solution to durability problem of concrete used in severe environment.

\section{Conclusions}

In order to find out the deterioration mechanism of the concrete materials used in a runway shoulder, many types of testing have been carried out, such as alkali-aggregate reaction testing, freeze-thaw cycles testing, and permeability testing. The following conclusions may be drawn from results of these investigations: the aggregates used in the concrete structure are nonreactive. Combined with other field and laboratory findings, there is little possibility of occurrence of alkali-aggregate reaction. The concrete cores from actual engineering only showed poor frost resistance and low impermeability. In addition, there were also cracking and pores in the paste of these cores through microstructure analysis. As a result, the severe environmental conditions plus the relatively inferior frost resistance cause the deterioration of the runway shoulder concrete. For the environmental condition where the actual engineering was situated, usage of air entraining admixture is an effective measure. Furthermore, new ideas and new approaches should be taken into consideration to solve the durability problem of concrete used in severe environment.

\section{Conflict of Interests}

The authors declare that they have no conflict of interests regarding the publication of this paper.

\section{Acknowledgments}

This research was supported by National Natural Science Foundation of China (no. 51108231), and Science and Technology Plan Projects of Ministry of Housing and Urban-rural Development of China (Grant no. 2013-K4-20).

\section{References}

[1] P. M. Eduardo, "Life cycle, sustainability and the transcendent quality of building materials," Building and Environment, vol. 42, no. 3, pp. 1329-1334, 2007.

[2] B. Ma, R. Dong, H. Zhu et al., "Influences of a new admixture MX on concrete durability," Journal Wuhan University of Technology, vol. 20, no. 1, pp. 117-120, 2005.

[3] B. Lulu, K. Joerg, and J. C. David, "Assessment of the durability of concrete from its permeation properties: a review," Construction and Building Materials, vol. 15, no. 2-3, pp. 93-103, 2001.

[4] M. Zhang and O. E. Gjørv, "Effect of silica fume on pore structure and chloride diffusivity of low parosity cement pastes," Cement and Concrete Research, vol. 21, no. 6, pp. 1006-1014, 1991.

[5] S. Mindess, J. F. Young, and D. Darwin, Concrete, Prentice Hall, New York, NY, USA, 2003.
[6] R. L. A. Male, "Pore structure and permeability of cementitious materials," Materials Research Society Symposium Proceedings, vol. 137, pp. 403-410, 1988.

[7] Y. Yun and Y. Wu, "Durability of CFRP-concrete joints under freeze-thaw cycling," Cold Regions Science and Technology, vol. 65, no. 3, pp. 401-412, 2011.

[8] W. Li, W. Sun, and J. Jiang, "Damage of concrete experiencing flexural fatigue load and closed freeze/thaw cycles simultaneously," Construction and Building Materials, vol. 25, no. 5, pp. 2604-2610, 2011.

[9] M. N. Haque and M. Kawamura, "Carbonation and chlorideinduced corrosion of reinforcement in fly ash concretes," $A C I$ Materials Journal, vol. 89, no. 1, pp. 41-48, 1992.

[10] P. K. Metha and P. Monterio, Concrete: Structure, Properties, and Materials, Prentice Hall, New York, NY, USA, 1993.

[11] H. K. Hilsdorf and J. Kropp, "Performance criteria for durability," RILEM Report 12, CRC Press, London, UK, 1995.

[12] P. E. Grattan-Bellew, "Microstructural investigation of deteriorated Portland cement concrete," Construction and Building Materials, vol. 10, no. 1, pp. 3-16, 1996.

[13] H. S. Shang and Y. P. Song, "Experimental study of strength and deformation of plain concrete under biaxial compression after freezing and thawing cycles," Cement and Concrete Research, vol. 36, no. 10, pp. 1857-1864, 2006.

[14] M. Tang and M. Deng, "Recent progress of studies on alkali aggregate reaction," Journal of Building Materials, vol. 6, no. 1, pp. 1-8, 2003.

[15] L. B. Mei, M. Deng, and M. S. Tang, "Advanced study on alkalicarbonate reactions in concrete," Journal of Nanjing University of Technology, vol. 24, no. 2, pp. 104-110, 2002.

[16] Z. W. Wu and H. Z. Lian, High Performance Concrete, China Railway Press, Beijing, China, 1999. 

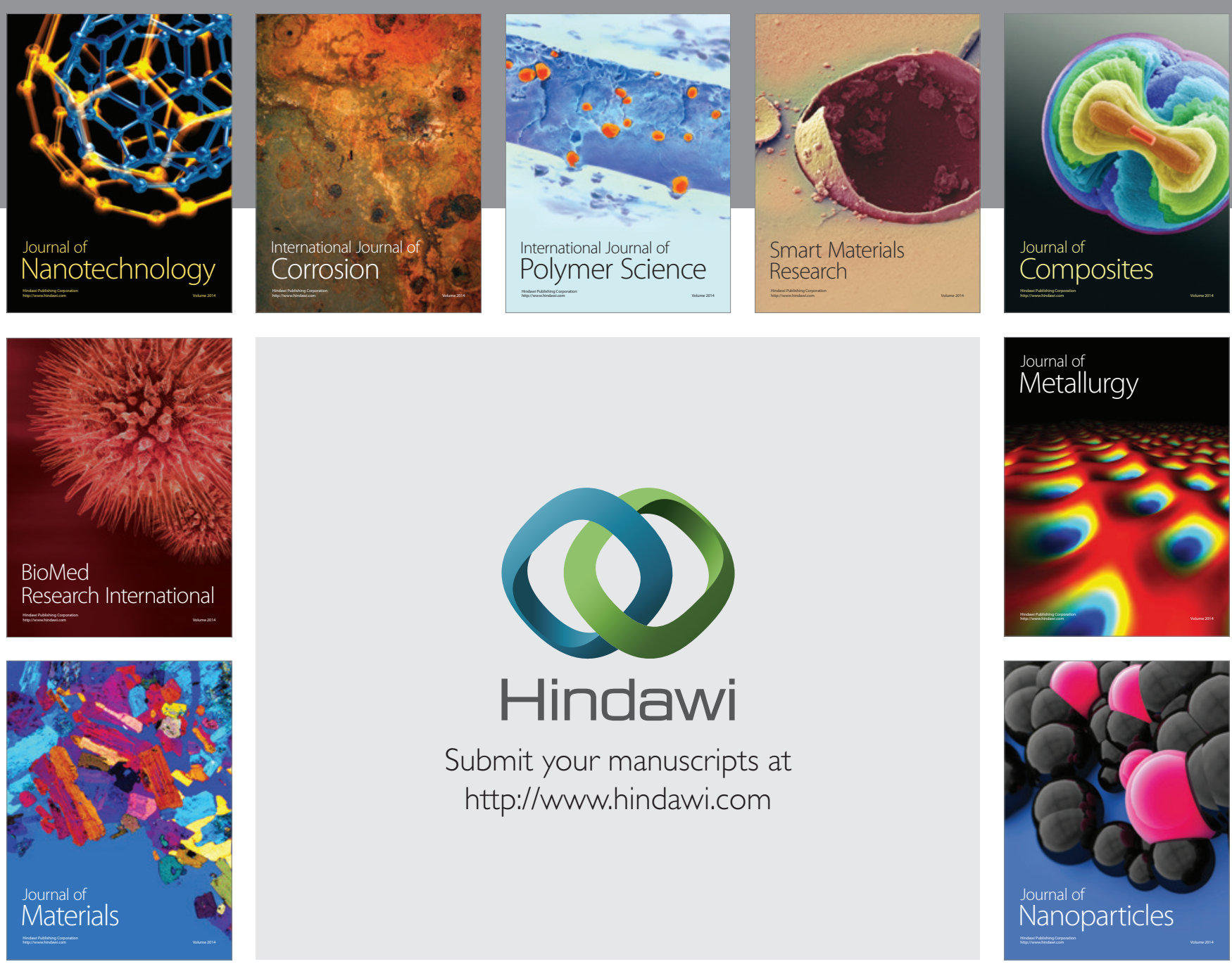

Submit your manuscripts at http://www.hindawi.com
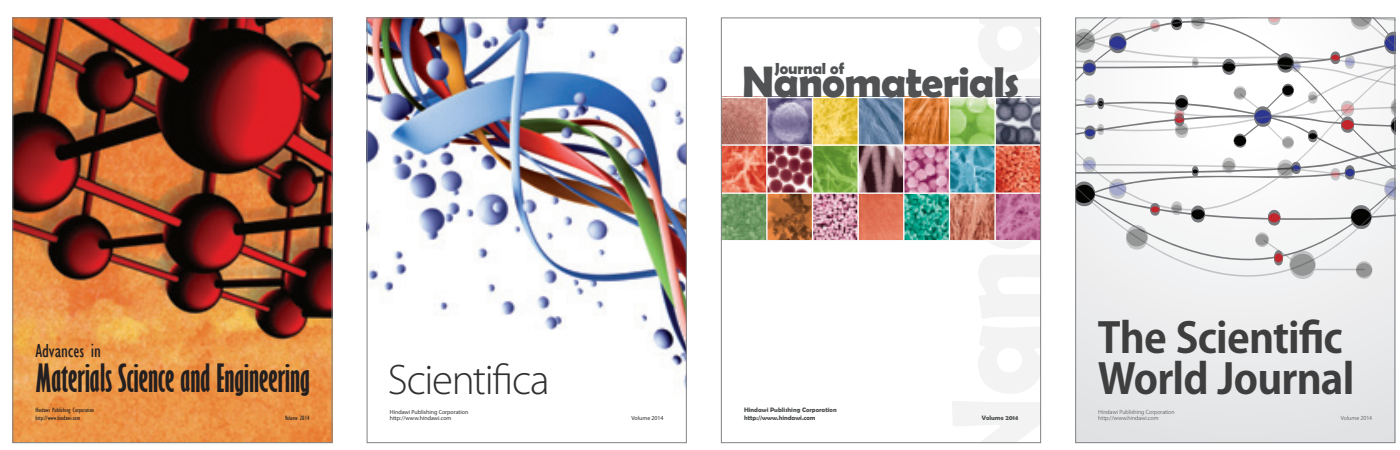

\section{The Scientific World Journal}
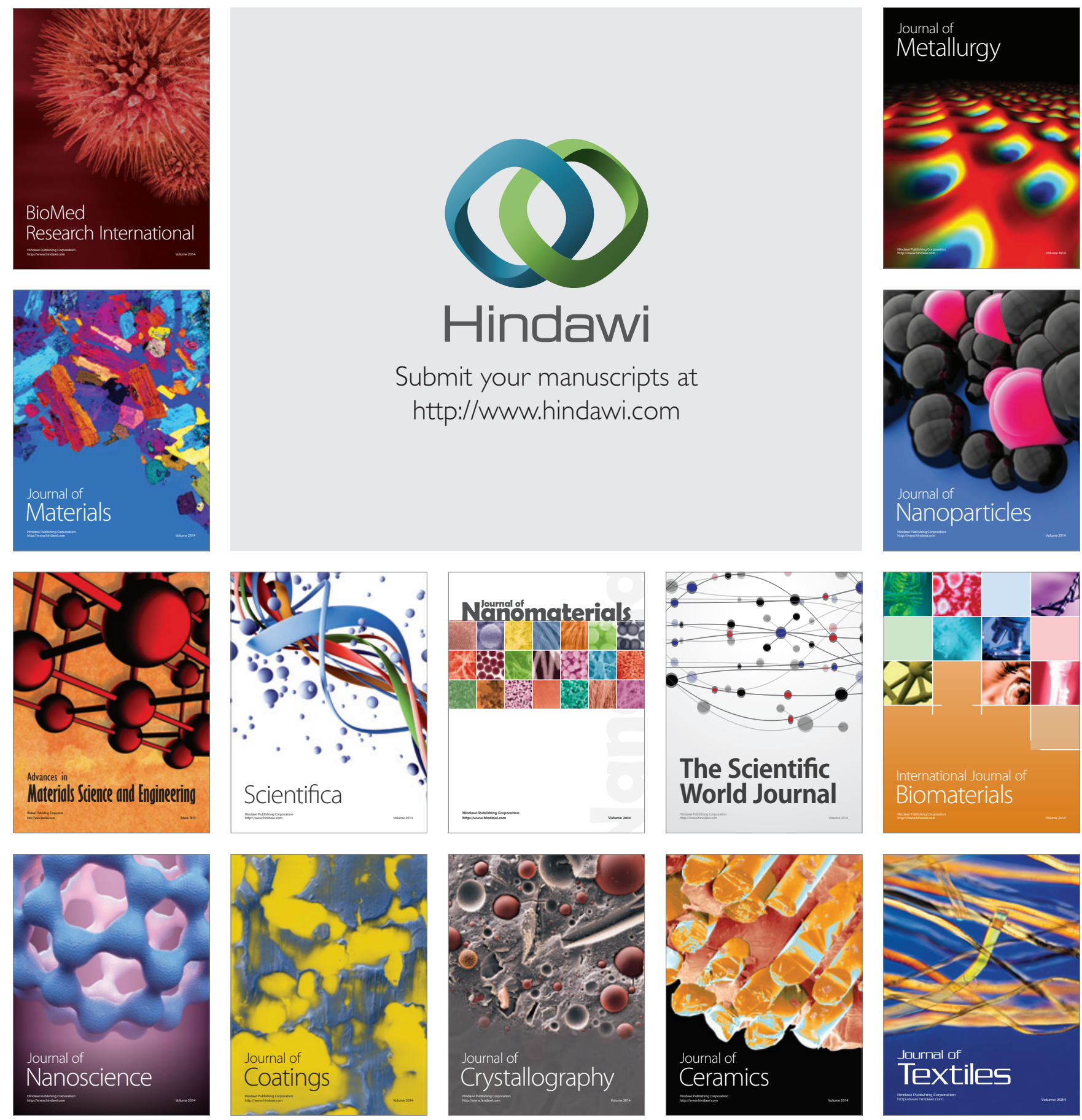